Original Article

\title{
EFFECT OF PSQI SCORE ON ADMINISTRATION MELATONIN IN PERIMENOPAUSE WOMEN
}

\author{
HANDRI R. VEBRIAN ${ }^{1}$, MUHAMMAD FIDEL GANISSIREGAR ${ }^{2}$, ICHWANUL ADENIN², HERBERT SIHITE², EDY \\ ARDIANSYAH $^{4}$, SARAH DINA ${ }^{5}$, PUTRI C. EYANOER ${ }^{6}$
}

1Department of Obstetrics and Gynecology, Faculty of Medicine, Universitas Sumatera Utara, ${ }^{2}$ Reproductive Endocrinology and Fertility Division, Departmen od Obstetrics and Gynecology Faculty of Medicine, Universitas Sumatera Utara, ${ }^{3}$ Fetomaternal Division, Departmen od Obstetrics and Gynecology Faculty of Medicine, Universitas Sumatera Utara, ${ }^{4}$ Urigynecology Division, Departmen od Obstetrics and Gynecology Faculty of Medicine, Universitas Sumatera Utara, ${ }^{5}$ Oncology Gynecology Division, Departmen od Obstetrics and Gynecology Faculty of Medicine, Universitas Sumatera Utara, ${ }^{\circ}$ Department of Community and Preventive Medicine, Faculty of Medicine, Universitas Sumatera Utara

Email: anditha.namira@gmail.com

Received: 15 Mar 2020, Revised and Accepted: 19 May 2020

\section{ABSTRACT}

Objective: Determine the effect of melatonin administration on sleep quality perimenopausal women based on PSQI and compare the results of PSQI before and after treatment.

Methods: This study uses an experimental analytic study with Case Control design to determine the effect of melatonin administration on sleep quality perimenopausal women based on PSQI and compare the results of PSQI before and after treatment. This research was conducted at the Department of Obstetrics and Gynecology, H. Adam Malik General Hospital, Medan. The study population was all perimenopausal women who met the inclusion and exclusion criteria. This research was conducted from February to March 2020 with a sample of 25 people.

Results: PSQI scores in the control group by age were $4.0 \pm 1.0$ in the age group $>50 \mathrm{y}$ from $8.0 \pm 1.0 ; 2.17 \pm 1.62$ in the group with tertiary education from $5.83 \pm 1.69 ; 2.56 \pm 1.67$ in the non-working group of $6.44 \pm 1.51$ and $2.31 \pm 1.6$ in the multipara group of $6.0 \pm 1.58$. From the analysis results obtained a value of $\mathrm{P}<0.001$. This also showed a significant difference in the PSQI score in the control group. significant differences in PSQI values in the control group and melatonin group in the case group before getting melatonin $(\mathrm{p}<0.001)$, whereas after administering melatonin, no difference in PSQI score was found in the groups that received melatonin and the control group $(p=0.657)$

Conclusion: There are differences in PSQI scores in the case group before and after the administration of melatonin, in the control group who did not get melatonin and the difference in PSQI scores in the case group and the control group before treatment, but there were no differences in PSQI score in the case and control groups after treatment.

Keywords: Perimenopause, Melatonin, PSQI

(C) 2020 The Authors. Published by Innovare Academic Sciences Pvt Ltd. This is an open access article under the CC BY license (http://creativecommons.org/licenses/by/4.0/) DOI: http://dx.doi.org/10.22159/ijcpr.2020v12i4.39097. Journal homepage: https://innovareacademics.in/journals/index.php/ijcpr

\section{INTRODUCTION}

Perimenopause is an obscure period time that surrounds the last years of a woman's reproductive life. Perimenopause begins with the first onset of menstrual irregularities and ends after women experience $1 \mathrm{y}$ of amenorrhea, which defines the end menstrual period (FMP). There are two stages of perimenopause or menopause transition: the initial transition, where the cycle is largely regular, with relatively few interruptions, and the final transition, where the amenorrhea becomes longer and lasts for at least $60 \mathrm{~d}$, until the FMP. Several cohorts around the world have defined the natural history of the menopause transition in enough detail so that these stages can be investigated and linked to certain hormonal events, which in turn are related to symptoms that appear in women [1].

Longitudinal study included Melbourne Healthy Women's Study [2], SWAN, the Study of Women's Health Across the Nation [3], and The Penn Ovarian Aging Study [4]. These studies have allowed us to define the process of transition to menopause more fully and reveal specific changes in symptoms related to certain transition stages. This long-term longitudinal cohort study includes a long follow-up period ( 9 and $20 \mathrm{y}$, respectively) and collects a lot of additional information about the quality of life, sexual function, bone density, and reproductive hormones. All of these studies are population-based or community-based, which are important considerations in efforts to define normal menopausal experiences for women. However, none of these studies assessed women with irregular menstrual cycles before the start of the menopause transition. This is because most of our definitions of menopause are still based on menstruation $[1,2,4]$.
Women begin to experience changes in their sleep patterns in their $40 \mathrm{~s}$, and this tends to worsen with entry into perimenopause [5]. The latest cohort study involving 255 women, unfortunately, did not examine sleep disturbance in perimenopausal women. But in the Melbourne Healthy Women's Study study, an increase in complaints about sleep deprivation was observed when women entered the perimenopause [6]. Significantly, older women complained more of insomnia compared to other demographic groups [7].

Sleep difficulties are seen to increase when women pass perimenopause, with a late menopause transition, and women who experience surgical menopause are reported to have the greatest sleep difficulties. In addition to the perimenopause stage, the time of sleep difficulties in the menstrual cycle is also explored at SWAN by conducting a daily estimate of sleep difficulties along with a daily urine hormone examination. In this study, sleep difficulties were related to the perimenstrual phase of the cycle, with early perimenopausal women overall experiencing worse sleep than women who had not experienced amenorrhoea. Health and quality of life and arthritis contribute to sleep deprivation complaints [8].

During the perimenopause to menopause, there are changes in 4 different neurotransmitter systems, such as the GAB Anergic, serotonergic (5HT), noradrenergic (NA) and dopaminergic (DA) systems. Both NA and DA are involved in sleep regulation. Changes in estrogen that depend on serotonin during the transition to menopause may be responsible for changes in sleep, mood, and memory [9].

For some women, sleep disorders may be temporary and thus do not require active treatment, whereas, for other women, sleep disorders 
may be severe, with a significant impact on daytime function and quality of life and thus the need for treatment. In addition, combination treatment may sometimes be needed, such as for women who experience depression in addition to severe vasomotor symptoms and sleep problems. The basis for the management of sleep disorders is good sleep hygiene: proper sleep environment, regular sleep-wake rhythm, adequate exercise, and avoidance of stimulants, eg, coffee, especially at night. Treatment options include Menopausal hormone therapy (MHT), non-hormonal pharmacological drugs, and nonpharmacological strategies and self-management [10].

Exogenous melatonin administration appears to have two physiological effects such as nocturnal melatonin secretion: stimulating sleep onset and maintenance and phase shifts in circadian rhythm, including rhythm in melatonin itself. Both are produced at physiological doses (ie, 0.1 up to $0.3 \mathrm{mg}$ for sleep and 0.3 to $0.5 \mathrm{mg}$ for phase changes, doses that increase plasma melatonin levels during the day to the normal nocturnal range observed in young adults) [11].

PSQI is an effective instrument for measuring sleep quality and patterns in older individuals. PSQI distinguishes "poor" from "good" sleep quality by measuring seven areas, namely, subjective sleep quality, sleep latency, sleep duration, the efficiency of sleep habits, sleep disturbances, use of sleeping pills, and daytime dysfunction in the past month [12].

\section{MATERIALS AND METHODS}

\section{Methods}

This study is an analytical study using a case-control design to determine the effect of melatonin administration on sleep quality perimenopausal women based on PSQI and compare the results of PSQI before and after treatment. This research was conducted at the Department of Obstetrics and Gynecology, H. Adam Malik General
Hospital, Medan. The study population was all perimenopausal women that have sleep disorder who came to H. Adam Malik General Hospital Medan. Perimenopause women who meet the research criteria as mentioned above, included in the subject perimenopause women with complaints of sleep disorders, have BMI $18,5-22,9 \mathrm{~kg} / \mathrm{m} 2$, and are willing to participate in this study. The steps taken in the sample are history taking, including name, age, parity, education, and profession. Then do a physical examination, including awareness, weight and height, and assess sleep quality using PSQI. The research procedure was the case and control groups were given the same treatment that is the recommendation of sleep schedule starting at $11 \mathrm{pm}$ in a comfortable and darkroom conditions. In the case group givenMelatonin $10 \mathrm{mg}$ tablets, with a dose of 1 tablet 1 time per day orally, taken 20 min before the sleep schedule, and carried out for 1 mo. Evaluate sleep quality using PSQI after being treated for 1 mo in both case and control groups. Do research data recording and researchanalysis. Data will be presented as a mean \pm standard deviation if the distribution is normal. If the distribution is not normal, the data will be presented in quartile form. Data were processed and analyzed using SPSS with a significance limit of $p<0.05$. To assess whether the sample is normally distributed or not the Kolmogorov-Smirnov test is performed. For statistical tests carried out on the data, it is performed by paired T-tests if the data is normally distributed, whereas if the data is not normally distributed will be used the Wilcoxon test.

\section{RESULTS}

A total of 25 samples were found that met the inclusion criteria and agreed to participate. From table 1 we found there was no differences in case and control characteristics based on age, BMI, diastolic blood pressure, education and occupation $(\mathrm{p}=0.769 ; \mathrm{p}=$ $0.061 ; p=0.210 ; p=0.304 ; p=1.00$ ). While based on systolic blood pressure and parity there were differences between the case and control groups $(\mathrm{p}=0.037 ; \mathrm{p}=0.03)$.

Table 1: Characteristic of subject

\begin{tabular}{|c|c|c|c|c|c|}
\hline Age (n, \%) & \multicolumn{2}{|c|}{ Case (n= 25) } & \multicolumn{2}{|c|}{ Control $(n=25)$} & \multirow[t]{2}{*}{ Pvalue } \\
\hline $45-50$ y old & 15 & $60.0 \%$ & 17 & $68.0 \%$ & \\
\hline$>50$ y old & 10 & $40.0 \%$ & 8 & $32.0 \%$ & \\
\hline BMI (mean+SD) & 20.86 & 1.35 & 21.38 & 1.17 & $0.061^{c}$ \\
\hline SBP (mean+SD) & 112.64 & 9.65 & 113.28 & 9.07 & $0.037^{c}$ \\
\hline $\mathrm{DBP}($ mean+SD) & 71.92 & 5.94 & 68.04 & 5.48 & $0.210^{c}$ \\
\hline \multicolumn{6}{|l|}{ Education } \\
\hline University & 7 & $28.0 \%$ & 9 & $36.0 \%$ & $0.304^{b}$ \\
\hline No University & 18 & $72.0 \%$ & 16 & $64.0 \%$ & \\
\hline \multicolumn{6}{|l|}{ Profession (n, \%) } \\
\hline Working & 9 & $36.0 \%$ & 9 & $36.0 \%$ & $1.00^{\mathrm{a}}$ \\
\hline Not Working & 16 & $64.0 \%$ & 16 & $64.0 \%$ & \\
\hline Parity (n, \%) & & & & & $0.03^{b}$ \\
\hline Primipara & 4 & $16.0 \%$ & 11 & $44.0 \%$ & \\
\hline Sekundipara & 6 & $24.0 \%$ & 1 & $4.0 \%$ & \\
\hline Multipara & 15 & $60.0 \%$ & 13 & $52.0 \%$ & \\
\hline
\end{tabular}

Based on table 2 we found that an increase in PSQI scores in the group before getting melatonin. After receiving melatonin, the mean PSQI score based on age was $2.38 \pm 1.75$ in the $45-50$ y age group from $8.24 \pm 2.59 ; 3.17 \pm 1.34$ in the group with No College education of
$8.89 \pm 2.56$; $3.0 \pm 1.32$ in the non-working occupation group of $8.38 \pm 2.22$ and $3.50 \pm 1.73$ in the primiparous group of $9.50 \pm 4.12$. From the analysis, results obtained a value of $\mathrm{P}<0.001$. This shows a significant difference in PSQI scores after the administration of melatonin.

Table 2: Comparison of PSQI scores in the group before and after giving melatonin

\begin{tabular}{|c|c|c|c|c|c|}
\hline \multirow[t]{3}{*}{ Age } & \multicolumn{4}{|c|}{ PSQI score } & \multirow[t]{3}{*}{ p value } \\
\hline & \multicolumn{2}{|c|}{ Pre } & \multicolumn{2}{|c|}{ Post melatonin } & \\
\hline & mean & sd & mean & sd & \\
\hline $45-50$ & 8.24 & 2.59 & 2.38 & 1.75 & $<0,001^{a}$ \\
\hline$>50$ & 9.75 & 2.06 & 2.25 & 2.06 & \\
\hline \multicolumn{6}{|l|}{ Education } \\
\hline No University & 8.89 & 2.56 & 3.17 & 1.34 & \\
\hline University & 7.43 & 2.30 & 0.29 & 0.49 & \\
\hline \multicolumn{6}{|l|}{ Profession } \\
\hline Not Working & 8.38 & 2.22 & 3.00 & 1.32 & \\
\hline Working & 8.67 & 3.16 & 1.22 & 1.92 & \\
\hline \multicolumn{6}{|l|}{ Parity } \\
\hline Primipara & 9.50 & 4.12 & 3.50 & 1.73 & \\
\hline Sekundipara & 9.83 & 1.94 & 2.67 & 1.86 & \\
\hline Multipara & 7.67 & 2.06 & 1.93 & 1.67 & \\
\hline
\end{tabular}

aWilcoxon rank test 
Based on table 3, It was found that there were differences in PSQI scores in the control group. The mean PSQI score of samples by age was $4.0 \pm 1.0$ in the age group $>50$ y from $8.0 \pm 1.0 ; 2.17 \pm 1.62$ in the group with tertiary education from $5.83 \pm 1.69 ; 2.56 \pm 1.67$ in the non- working group of $6.44 \pm 1.51$ and $2.31 \pm 1.6$ in the multipara group of $6.0 \pm 1.58$. From the analysis, results obtained a value of $\mathrm{P}<0.001$. This also showed a significant difference in the PSQI score in the control group.

Table 3: Comparison of PSQI score in the control group

\begin{tabular}{|c|c|c|c|c|c|}
\hline & \multicolumn{4}{|c|}{ PSQI score } & \multirow[t]{3}{*}{ p-value } \\
\hline & \multicolumn{2}{|l|}{ Pre } & \multicolumn{2}{|l|}{ Post } & \\
\hline & mean & SD & mean & SD & \\
\hline Age & & & & & $<0,001^{a}$ \\
\hline $45-50$ & 5.64 & 1.43 & 1.91 & 1.48 & \\
\hline$>50$ & 8.00 & 1.00 & 4.00 & 1.00 & \\
\hline \multicolumn{6}{|l|}{ Education } \\
\hline No University & 6.14 & 1.35 & 2.14 & 1.57 & \\
\hline University & 5.83 & 1.69 & 2.17 & 1.62 & \\
\hline \multicolumn{6}{|l|}{ Profession } \\
\hline Not Working & 6.44 & 1.51 & 2.56 & 1.67 & \\
\hline Working & 5.63 & 1.59 & 1.94 & 1.53 & \\
\hline \multicolumn{6}{|l|}{ Parity } \\
\hline Primipara & 6.09 & 1.45 & 2.18 & 1.54 & \\
\hline Sekundipara & 3.00 & & 0.00 & & \\
\hline Multipara & 6.00 & 1.58 & 2.31 & 1.60 & \\
\hline
\end{tabular}

Based on table 4, There was significant differences in PSQI values in the control group and melatonin group with a PSQI score of $5.92 \pm 1.57$ in the control group and $8.48 \pm 2.53$ in the case group before getting melatonin $(\mathrm{p}<0.001)$, whereas after administering melatonin, no differences were found in the PSQI score scores in the groups receiving melatonin and the control group, with PSQI scores of $2.36(0-5.0)$ and $2.16(0-5.0) ;(\mathrm{p}=$ $0.657)$.

Table 4: Comparison of PSQI score in the control group and melatonin group before and after treatment

\begin{tabular}{|c|c|c|c|c|c|c|}
\hline & $\mathbf{N}$ & Cont & & Mela & $n=25)$ & p value \\
\hline PSQI pre (mean \pm sd) & 25 & 5,92 & 1,57 & 8,48 & 2,53 & $<0.001^{a}$ \\
\hline PSQI Post (median (min-max)) & 25 & 2,16 & $0-5.0$ & 2.36 & $0-5.0$ & $0.657^{b}$ \\
\hline
\end{tabular}

andependent T-test (normal distribution), bWilcoxon rank test (abnormal distribution)

\section{DISCUSSION}

Melatonin plays a role in circadian rhythms, especially in terms of sleep quality. In per menopause, difficulty sleeping is one of the symptoms that is often found in the per menopause period. Melatonin also plays a role in the improvement of climacteric symptoms, including symptoms of psychological, somatic, vasomotor, and sexual disorders. From the results of this study, there were no differences in case and control characteristics based on age, BMI, diastolic blood pressure, education and occupation ( $\mathrm{p}=$ $0.769 ; \mathrm{p}=0.061 ; \mathrm{p}=0.210 ; \mathrm{p}=0.304 ; \mathrm{p}=1.00$ ). While based on systolic blood pressure and parity, there were differences between the case and control groups $(p=0.037 ; p=0.03)$.

Our results are in line with the report, Penn Ovarian Aging Study [5]. This finding is also in line with the Melbourne Healthy Women's Study Study, an increase in complaints about sleep deprivation was observed when women entered the perimenopause [6]. Significantly, older women complained more of insomnia compared to other demographic groups [7]. However, it is unclear whether these observations are directly related to perimenopause, decreased estrogen levels, or other hormonal changes, or whether these sleep disorders occur only because of the aging process [1].

From our study, from the analysis carried out in the dick group and case group (melatonin), there were differences in PSQI scores at the beginning of the study $(\mathrm{p}<0.001)$ while in the analysis conducted in the two groups after treatment in the melatonin group, no differences were found, which is significant on the PSQI score ( $p=$ 0.657). This suggests that the administration of melatonin is no more effective than control in improving sleep quality in perimenopausal women and no significant differences are found.

Difficulty in sleep increases when a woman passes through perimenopause, with the menopause transition. In addition to the perimenopause stage, the time of sleep difficulties in the menstrual cycle is also explored in the SWAN study by conducting daily estimates of sleep difficulties along with daily urine hormone examination [8]. In this study, unfortunately, we did not measure PSQI scores and compare patient hormone levels in the menstrual cycle.

This is in accordance with the Meta-analysis conducted by Ferracioli-Oda et al., which shows melatonin has a significant benefit in reducing sleep latency. Subjects randomly given melatonin fell asleep 7 min earlier than the average placebo subject (mean time difference $(\mathrm{WMD})=7.06 \mathrm{~min}[95 \% \mathrm{CI}: 4.37$ to 9.75$], \mathrm{Z}=5.15$, $\mathrm{p}<0.001)$. There was significant evidence of heterogeneity between trials $(\mathrm{Q}=31.9, \mathrm{df}=14, \mathrm{p}=0.004, \mathrm{I} 2=56 \%)$. In a randomized model, sleep latency was reduced by more than $10 \mathrm{~min}(\mathrm{WMD}=10.18 \mathrm{~min}$ [95\% CI: 6.1 to 14.27$], Z=4.88, p, 0.001$ ). We found no significant evidence of publication bias based on Egger's Test (intercept $=1.08$, [95\% CI: 20.35 to 2.52], $\mathrm{t}=1.62, \mathrm{p}=0.12$ ). Stratification trials with objective and subjective measures of sleep onset did not significantly reduce heterogeneity between trials $(Q=3, d f=1, p=0.08)$. Melatonin significantly reduces sleep latency for both goals $(\mathrm{WMD}=5.50 \mathrm{~min}$ [95\% $\mathrm{CI}=2.29$ to 8.71], $\mathrm{Z}=3.36, \mathrm{p}, 0.001$ ) and subjective action (WMD $=10.68 \mathrm{~min}$ [95\% CI: 5.78 to 15.58$], \mathrm{z}=4.27, \mathrm{p}, 0.001$ ). Metaregress shows that trials with longer duration (estimated parameter $(\mathrm{PE})=$ 0.53 [95\% CI $=0.21$ to 0.86$], p=0.001$ ) reported a greater effect on sleep latency. Trials using higher doses of melatonin also reported a greater effect of melatonin on sleep latency at a trend level $(\mathrm{PE}=1.95$ [95\% $\mathrm{CI}=20.00$ to 3.91], $\mathrm{p}=0.05$ ] [13].

In line with the research of Ferracioli-Oda et al., melatonin showed a significant effect in improving sleep quality. Subjects randomly given melatonin experienced improved sleep quality compared with placebo (standard mean difference (SMD) $=0.22$ [95\% CI: 0.12 to $0.32], \mathrm{Z}=4.52, \mathrm{p}, 0.001)$. There was no significant evidence of heterogeneity differences between the observed trials $(Q=11.59$, df 
$=13, \mathrm{p}=0.56, \mathrm{I} 2=0$ ). Giving melatonin and placebo provides the same overall effect. We found no evidence of significant differences based on the Egger's Test (intercept $=20.13$ [95\% CI: 21.08 to 0.81 ], $\mathrm{t}=0.30, \mathrm{p}=0.76$ ). Stratification trials with objective and subjective measures of sleep quality did not reduce heterogeneity between trials $(\mathrm{Q}=0.05, \mathrm{df}=1, \mathrm{p}=0.82)$. Melatonin improves sleep quality to the same level in both subjectively (SMD $=0.23$ [95\% CI: 0.12-0.34], $\mathrm{Z}=4.23, \mathrm{p}, 0.001)$ and objective measures (SMD $=0,20[95 \% \mathrm{CI}$ : 20.04 to 0.44$], \mathrm{Z}=1.61, \mathrm{p}=0.10$ ). The meta-regression did not show a significant effect on theduration of the trial $(\mathrm{PE}=0.005[95 \% \mathrm{CI}$ : $20,0006$ to 0.012$], \mathrm{p}=0.08$ ) or melatonin dose onsleep quality (PE = 0.011 [95\% CI: 20.114 to 0.090 ], $\mathrm{p}=0.81$ ] [13].

In their study, Ferracioli-Oda et al. reported that melatonin also significantly increased total sleep time compared to placebo. Subjects randomly assigned to melatonin had an average total sleep time of 8 min longer than subjects taking placebo $(\mathrm{WMD}=8.25 \mathrm{~min}$ [95\% CI: 1.74-14.75], $\mathrm{Z}=2.48, \mathrm{p}=0.013$ ). there was significant heterogeneity between trials $(\mathrm{Q}=21.44$, df $=12, \mathrm{p}=0.044, \mathrm{I} 2=$ $44 \%$ ). Total sleep time increased by $8 \mathrm{~min}$ in the random-effects model $(\mathrm{WMD}=8.48 \mathrm{~min}$ [95\% CI: 24.02 to 20.98 ], $\mathrm{Z}=1.33, \mathrm{p}=$ $0.184)$. We did not find any bias in this study based on the Egger's Test (intercept $=0.3$ [95\% CI: 20.9 to 1.7], $\mathrm{t}=0.6, \mathrm{p}=0.52$ ). Stratification trials with objective or subjective measures of total sleep time are used to reduce heterogeneity at the trend level $(\mathrm{Q}=$ 2.6, $\mathrm{df}=1, \mathrm{p}=0.10$ ). Melatonin significantly increased total sleep time with subjective measurements $(\mathrm{WMD}=11.93 \mathrm{~min}[95 \% \mathrm{CI}$ : 4.06 to 19.81$], \mathrm{Z}=2.91, \mathrm{p}=0.002$ ) but not on objective measurements (WMD $=0,33 \mathrm{~min}$ [95\% CI: 211.19 to 11.87 ], $\mathrm{Z}=$ $0.05, \mathrm{p}=0.95)$. The meta-regression showed that trials with longer duration ( $\mathrm{PE}=1.60$ [95\% CI: 0.50 to 2.69], $\mathrm{p}=0.004$ ) reported a greater effect on total sleep time, as well as trials using high dose melatonin (PE = 7.25 [95]\% CI: 1.94 to 12.56], $\mathrm{p}=0.007$ ) [13]

\section{CONCLUSION}

There were no differences in characteristics and controls based on age, BMI, diastolic blood pressure, education and occupation $(\mathrm{p}=$ $0.769 ; \mathrm{p}=0.061 ; \mathrm{p}=0.210 ; \mathrm{p}=0.304 ; \mathrm{p}=1.00)$. While based on systolic pressure and parity there were differences between the case and control groups $(p=0.037 ; p=0.03)$. There was a difference in PSQI scores in the case group before and after melatonin administration $(\mathrm{p}<0.001)$. There were differences in PSQI scores in the control group who did not get melatonin $(p<0.001)$. There were differences in PSQI scores in the case and control groups before the meeting $(\mathrm{p}<0.001)$, but there were no differences in PSQI scores in the case and control groups after training $(p=0.657)$.

\section{FUNDING}

Nil

\section{AUTHORS CONTRIBUTIONS}

All the authors have contributed equally.

\section{CONFLICT OF INTERESTS}

Declared none

\section{REFERENCES}

1. Santoro N. Perimenopause: from research to practice. J Women's Health 2016;25:332-9.

2. Burger HG, Dudley E, Mamers P, Groome N, Robertson DM. Early follicular phase serum FSH as a function of age: the roles of inhibin B, inhibin A and estradiol. Climacteric 2000;3:17-24.

3. Santoro N, Randolph JF Jr. Reproductive hormones and the menopause transition. Obstetrics Gynecol Clin North America 2011;38:455-66.

4. Freeman EW, Sammel MD, Lin H. Temporal associations of hot flashes and depression in the transition to menopause. Menopause (New York, NY) 2009;16:728-34.

5. Freeman EW, Sammel MD, Gross SA, Pien GW. Poor sleep in relation to natural menopause: a population-based 14-year follow-up of midlife women. Menopause (New York, NY) 2015;22:719-26.

6. Dennerstein L, Lehert P, Guthrie JR, Burger HG. Modeling women's health during the menopausal transition: a longitudinal analysis. Menopause (New York, NY) 2007;14:53-62.

7. Bixler EO, Kales A, Soldatos CR, Kales JD, Healey S. Prevalence of sleep disorders in the los angeles metropolitan area. Am J Psychiatry 1979;136:1257-62.

8. Kravitz HM, Joffe H. Sleep during the perimenopause: a SWAN story. Obstetrics Gynecol Clin North America 2011;38:567-86.

9. Durant C, Christmas D, Nutt D. The pharmacology of anxiety. Curr Top Behav Neurosci 2010;2:303-30.

10. Polo Kantola P, Saaresranta T, Lampio LRF, Perez Lopez. editors. United States: Springers International Publishing; 2019.

11. Vural EM, van Munster BC, de Rooij SE. Optimal dosages for melatonin supplementation therapy in older adults: a systematic review of current literature. Drugs Aging 2014;31:441-51.

12. Smyth $C$. The pittsburgh sleep quality index (PSQI). Director 2000;8:28-9.

13. Ferracioli Oda E, Qawasmi A, Bloch MH. Meta-analysis: melatonin for the treatment of primary sleep disorders. PloS One 2013;8:e63773 